\title{
INFECTIONS IN URINARY TRACT OF PATIENTS WITH HAEMATOLOGICAL MALIGNANCIES UNDERGOING ANTINEOPLASTIC THERAPY
}

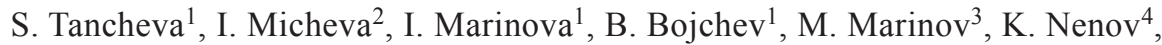 \\ R. Radev ${ }^{3}$ \\ ${ }^{1}$ Department of Clinical Laboratory \\ ${ }^{2}$ Department of Internal Medicine-Haematology Division \\ University Hospital, Medical University - Varna, \\ ${ }^{3}$ Department of Preclinical and Clinical Medical Sciences, Medical University \\ - Varna, \\ ${ }^{4}$ Department of Internal Medicine-Nephrology and Haemodialysis Division, \\ University Hospital, Medical University - Varna,
}

\begin{abstract}
The treatment of the malignant diseases requires the use of combination chemotherapy in multiple cycles administered to achieve adequate tumor cell kill without lifethreatening toxicity or the development of tumor cell resistance. Patients and methods: 72 patients (48 women and 24 men, median age -47 , from 24 to 71years with urinary tract infections (UTI), hospitalized in the Clinic of Hematology for the period January 2006-May 2008. Urinalysis: microscopic examination - white blood cells (WBC), bacteria; urine culture; sensitivities of culture.

Blood tests: urea (kinetic UV test ), creatinin (Jaffe kinetic), CRP (immunoturbidimetric method), blood culture, sensitivities of culture. Results and conclusions: The urinary tract infections are a common complication during the combination chemotherapy patients with hematological malignancies. For the period 2006-2008, 72 patients undergoing combination chemotherapy were diagnosed with UTI.
\end{abstract}

Keywords: urinary tract infections; antineoplastic therapy; Beta-2 microglobulin

\section{INTRODUCTION:}

The treatment of the malignant diseases requires the use of combination chemotherapy in multiple cycles administered to achieve adequate tumor cell kill without lifethreatening toxicity or the development of tumor cell resistance. As opposed to many other classes of drugs, the therapeutic window for chemotherapeutic agents is narrow (4). The dose of drug needed to achieve adequate tumor cell kill often causes toxicity to normal tissues. Infection is the major cause of morbidity and mortality in patients undergoing antineoplastic chemotherapy (3). The most important risk factor for infection in patients with hematologic diseases is absolute neutropenia. Other coexisting conditions, the common sequelae of hematologic malignancy or its therapy, further add to the risk of infection in neutropenic patients. These include defects in humoral and cell-mediated immunity (functional asplenia, hypogammaglobulinemia, phagocyte and T-cell dysfunction); mucosal damage resulting from chemotherapy; disruption of physical barriers by intravascular catheter devices, local hemorrhage, or tumor infiltration; alterations in normal flora; and impairment of central nervous system reflexes (micturition) (1).

The most common sites of infection in neutropenic patients include the lung, oropharynx, blood, urinary tract, skin, and soft tissues, including the perirectal area. Infections are generally caused by organisms already colonizing the patient, although some of these organisms are acquired after admission to the hospital $(3,6)$.

The aim of the present study was to analyse the cases of urinary tract infections in patients with hematological malignancies, undergoing combination chemotherapy.

\section{PATIENTS AND METHODS:}

Seventy-two patients (48 women and 24 men, median age -47 , from 24 to 71 years) with urinary tract infections (UTI), hospitalized in the Clinic of Hematology for the period January 2004 - May 2006, were analysed.

Eight of the patients had acute leukemia, 20 chronic myeloid leukemia, Nonhodgkin Lymphoma, 4 Hodgkin disease, 13 Chronic lymphocytic leukemia, 10 Multiple myeloma, 8 Myelodysplastic Syndrome.

The diagnosis UTI was based on the patient history and the following laboratory tests:

Urinalysis + microscopic examination: white blood cells (WBC), bacteria; urine culture; sensitivities of culture

Blood tests-* urea (kinetic UV test), creatinin (Jaffe 
kinetic), CRP (immunoturbidimetric method), blood culture, sensitivities of culture

\section{RESULTS:}

Thirty-six from 72 patients had history of dysuria. Bacteriuria was detected in 68 from 72 patients.

In 49 patients $(68 \%)$ bacteriuria was significant $\left(10^{5}\right.$ colonies per $\mathrm{ml}, 10^{2}$ to $10^{4}$ colonies per $\mathrm{ml}$ was accepted as significant if patient was symptomatic).

Nineteen from 68 patients (26.4\% from all patients) had insignificant bacteriuria. Twelve from the patients with significant bacteriuria were asymptomatic (Fig. 1).

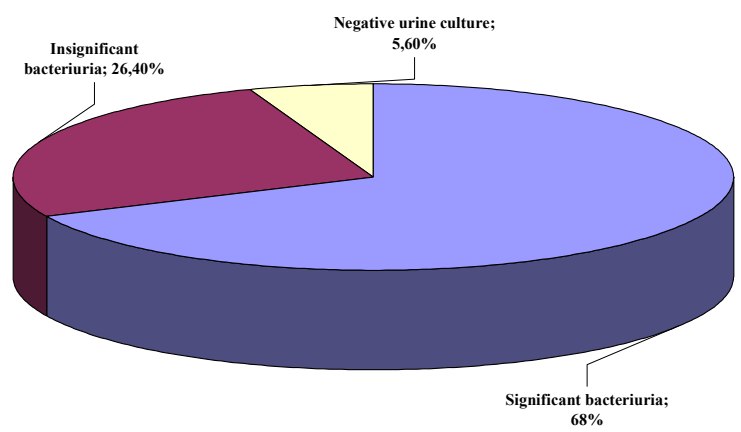

Fig. 1. Percentage of patients with bacteriuria

E. coli was isolated from the urine culture in 44 from 68 patients $(64.7 \%)$.

In the rest 24 patients Enterococcus faecalis, Enterococcus specyes, Proteus mirabilis, Acynetobacter, Pseudomonas aeroginosa, Klebsiella pneumoniae and mixed infection were detected (Fig. 2.).
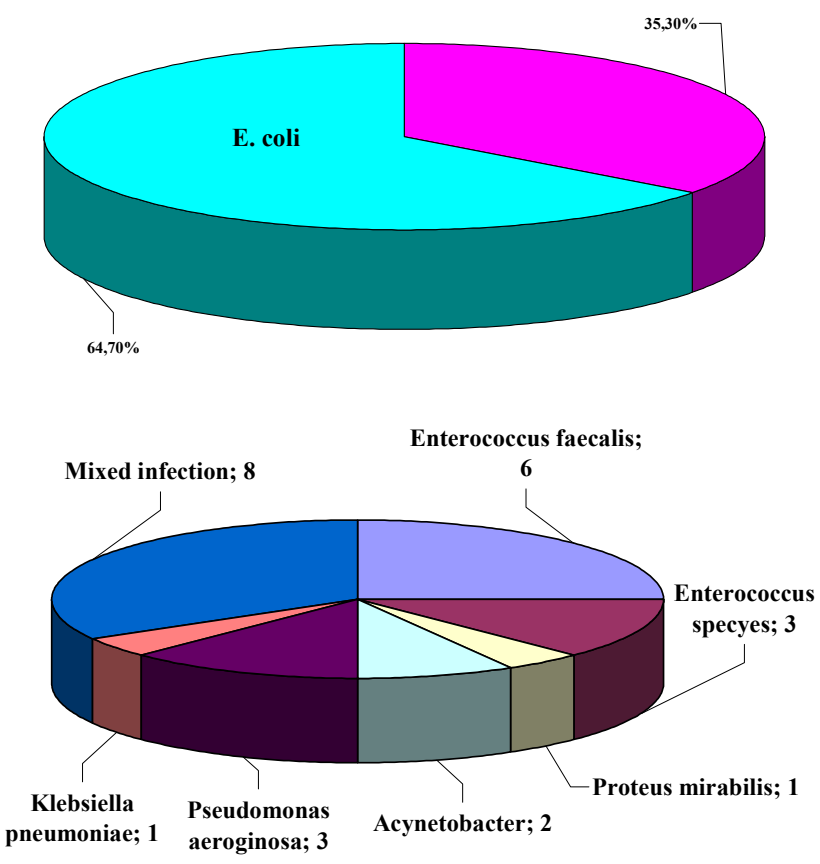

Fig. 2. Percentage of patients with E. coli infection and number of patients with other than E. coli infection.

In 5 from 72 patients urosepsis was diagnosed - the pathogenic agent was isolated both from the urine and the blood culture. The cause for urosepsis was E.coli in 2 cases, Pseudomonas aeroginosa in 2 cases and Acynetobacter in 1 case (Fig. 3.).

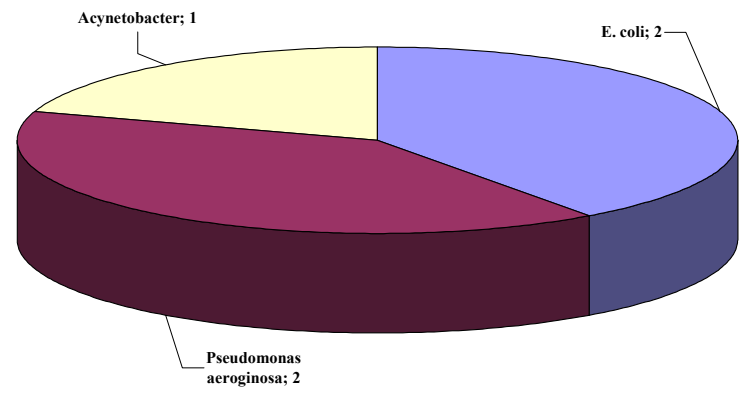

Fig. 3. Number of patients with pathogenic agent isolated both from the urine and the blood culture.

CRP was increased in 25 patients, however its significance is undetermined because it is a nonspecific marker for inflammation (Fig. 4.).

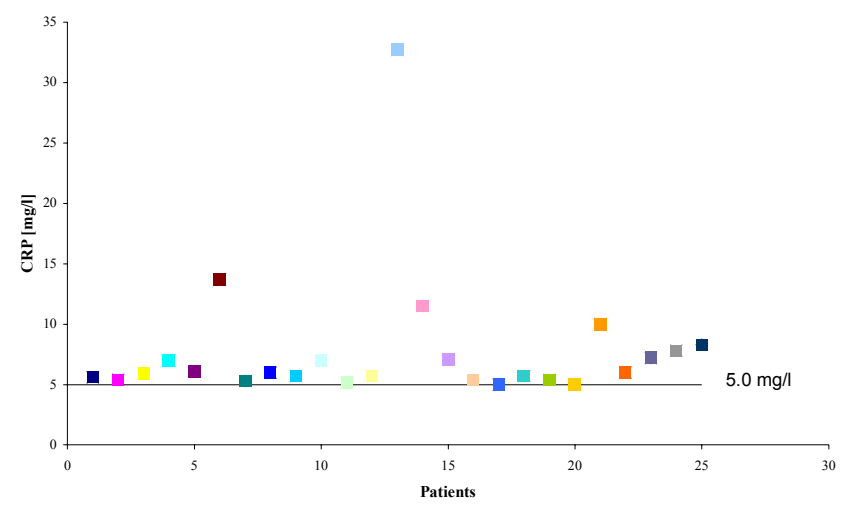

Fig. 4. Increased CRP values in 25 patients. Range of values $0.58-5.0 \mathrm{mg} / \mathrm{l}$.

In 7 from 72 patients high levels of urea were measured, whereas increased creatinine values over the normal range were detected only in two of the cases with decreased renal function before the initiation of UTI 


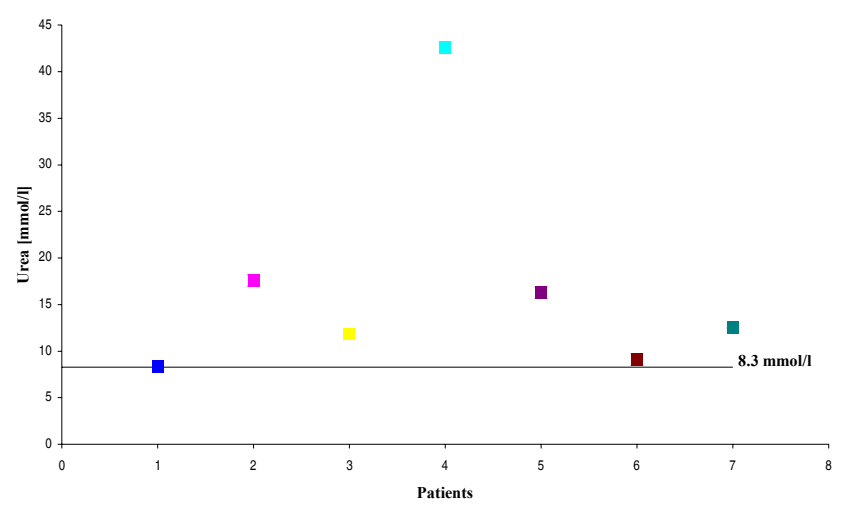

Fig. 5. Increased Urea and Creatinine values in 7 patients. Range of values: Urea $-1.7-8.3 \mathrm{mmo} / \mathrm{l}$; Creatinine $-44-134 \mathrm{Mmol} / \mathrm{l}$.

In 11 from 72 patients the sensitivities of culture showed resistance to the most commonly used antibiotic therapy.

Increased number of white blood cells in the urine (pyuria) was found in 70 from 72 patients (Fig. 6).

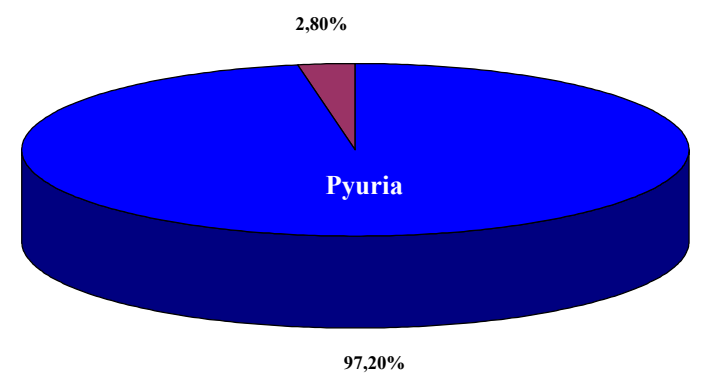

Fig. 6. Percentage of patients with and without pyuria.

\section{CONCLUSIONS:}

The urinary tract infections are a common complication during the combination chemotherapy in patients with hematological malignancies (2). For the period 2004-2006, 72 patients undergoing combination chemotherapy were diagnosed with UTI. Women suffer more often from this complication, probably due to short urethra, proximity to anus or colon dysfunction. Diagnosis was based on the laboratory finding of pyuria and/or bacteriuria. E. coli emerged the major cause of UTI $(5,7)$. However, Enterococcus faecalis, Enterococcus species, Proteus mirabilis, and Acynetobacter were also detected as etiologic pathogens in these patients. On the ground of the laboratory tests that were analysed, including urea and creatinine, it is impossible to specify the primary localization of the UTI.

Beta2-microglobulin is a low molecular protein (11 800 D). It is synthesised in all nucleated cells. Because of its low molecular weight it is filtered in the glomerules and reabsorbed in the proximal tubules $99.9 \%$. Thus, $\left(Я_{2}-\right.$ microglobulin is one of the most sensitive markers for tubular dysfunction and can be used to determine the localisation of the urinary tract infection.

\section{REFERENCES:}

1. Ashour H.M., A. el-Sharif. Microbial spectrum and antibiotic susceptibility profile of gram-positive aerobic bacteria isolated from cancer patients.Clin Oncol, 2007, 25: 5763-5769.

2. Aisenberg G., K. V. Rolston, A. Safdar. Bacteremia caused by Achromobacter and Alcaligenes species in 46 patients with cancer (1989-2003). Cancer, 2004, 101: 2134-2140.

3. Choi S. H., J. H. Woo, J.Y. Jeong, N.J Kim., M. N. Kim, Y.S. Kim, J. Ryu. Clinical significance of Staphylococcus saprophyticus identified on blood culture in a tertiary care hospital. Diagn Microbiol Infect Dis, 2006, 56: 337-339.

4. Cordonnier C., R. Herbrecht, J.L. Pico, M. Gardembas et al. Cefepime/ amikacin versus ceftazidime/amikacin as empirical therapy for febrile episodes in neutropenic patients: a comparative study. The French Cefepime Study Group.Clin Infect Dis, 1997, 24: 41-51.

5. Maschmeyer G., W. Hiddemann, H. Link, O.A. Cornely, D. Buchheidt, B. Glass,
D. Adam. Management of infections during intensive treatment of hematologic malignancies. Ann Hematol, 1997, 75: 9-16.

6. Olesen B, H.J. Kolmos, F. Orskov, I. Orskov, A. Gottschau. Bacteraemia due to Escherichia coli in a Danish university hospital, 1986-1990. Scand J Infect Dis, 1995, 27: 253-257.

7. Simon A., G. Fleischhack. Surveillance nosokomialer Infektionen in der рдdiatrischen Ндтаtologie/Onkologie. Klin Padiatr, 2001, 213, Suppl 1: A106-113.

\footnotetext{
Address for correspondence:

Radko Zl. Radev

Medical University-Varna

Marin Drinov 55, 9002 Varna

052677050 - 2657

e-mail: pathophysiology@mu-varna.bg
} 